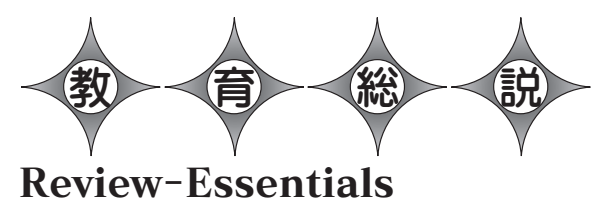

\section{Anterior Extra Pharyngeal Approach and Fixation of the Atlanto-axial Joint with Screw Plate Construct or Anterior Transarticular Screws : and Review of Literature}

\author{
Sushil Patkar, M.D. \\ Bhartividyapeeth Medical College and Hospital \\ Poona Hospital \& Research Center
}

Key words :

atlanto-axial fusion

anterior transarticular screws anterior screw plate fixation atlanto-axial dislocation

\begin{abstract}
Both the atlanto-axial joints can be exposed adequately by an unilateral extra-pharyngeal approach from the right side. The atlanto-axial dislocation can be reduced, joints can be decorticated and bone graft can be introduced into the joint. The odontoid process can be drilled and removed. The $\mathrm{C} 1-\mathrm{C} 2$ joint can be fixed either by 1. C1 lateral mass and C2 body screw plate bilaterally, or 2. Bilateral anterior $\mathrm{C} 2-\mathrm{C} 1$ transarticular screws.
\end{abstract}

\section{Material and method}

Since 2008, 62 patients, 39 patients anterior trans articular screws, 23 patients anterior screw plate fixation, 40 males 22 females, AAD 42, tuberculosis 12, fixed AAD with basilar invagination 8 . All patients underwent preop-

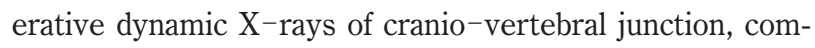
puterized tomography (CT scan) of $\mathrm{C} 1-\mathrm{C} 2$ static and dynamic study with bone window settings and 3D reconstruction, magnetic resonance imaging (MRI) and MR angiography to study course of vertebral artery.

\section{Operative technique}

Anaesthesia: Awake endoscopic nasal intubation and general anaesthesia.

Position : Supine with extension of the head and mild rotation to left side, lateral $\mathrm{X}$-ray image to confirm that mandible is at or above $\mathrm{C} 2$ body on extending the head.

Skull tongs applied for intra operative manipulation.

Stevenson's ${ }^{1)}$ technique for exposure to reach the prevertebral space at $\mathrm{C} 1-\mathrm{C} 2$.

Curved from midline to angle of mandible at a distance of $2 \mathrm{cms}$ below the mandibular margin to protect the marginal mandibular nerve. Skin and platysma flaps reflected bilaterally. Mylohyoid muscle divided from the midline to the angle of the mandible. Upper flap of mylohyoid muscle reflected upwards to expose the mandibular gland and the digastric muscle and stylohyoid muscle (Fig. 1-5). Both muscles disconnected from the hyoid bone and reflected upwards to identify the hypoglossal nerve. Hypoglossal nerve separated from surrounding connective tissue to mobilize it upwards for 1-2 cms.

Facial artery and vein identified and protected. Internal carotid artery pulsations felt and plane of dissection just medial to the artery to reach the retropharyngeal space on the anterior aspect of the $\mathrm{C} 2$ body. $\mathrm{X}$-ray imaging is performed to confirm position. Long bladed Langenbeck's retractors $(6-8 \mathrm{cms})$ used and anterior surface of $\mathrm{C} 1$ exposed with electrocautery and periosteal elevators. The $\mathrm{C} 2$ body was cleared of all soft tissue, anterior longitudinal ligament and longus colli divided to expose the atlanto-axial joints bilaterally. The anterior joint capsule was cut with a no. 15 blade and the synovium exposed. The joint cartilage on either side was curetted with a $2-3 \mathrm{~mm}$ angled Karlin's curette till the posterior margin of the joint. Skull traction could be used manipulate and distract the joint for satisfactory decortications of both the $\mathrm{C} 1$ and C2 lateral mass surfaces of the joint till there was some bleeding from the cortical endplates. In cases with fixed C1-C2 dislocation all soft tissue between anterior arch of $\mathrm{C} 1$ and odontoid process was removed, a microdrill was used to drill a hole of $3 \mathrm{~mm}$ into the base of the odontoid 


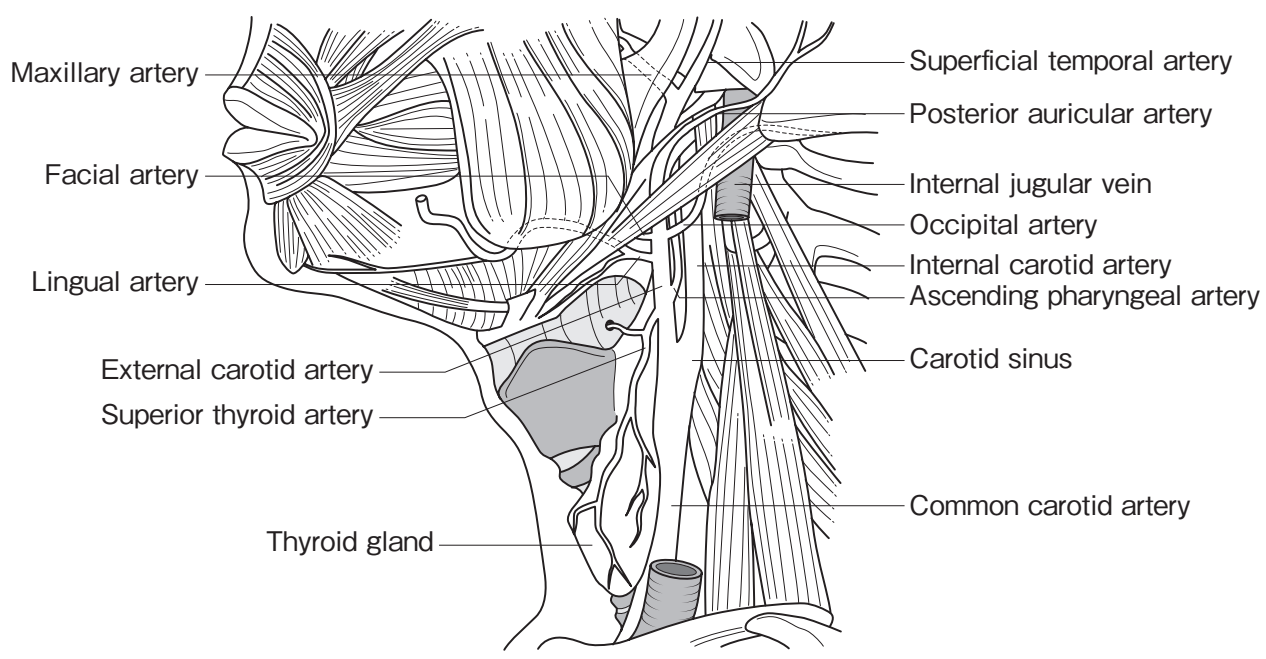

Fig. 1 Anatomy of neck muscles
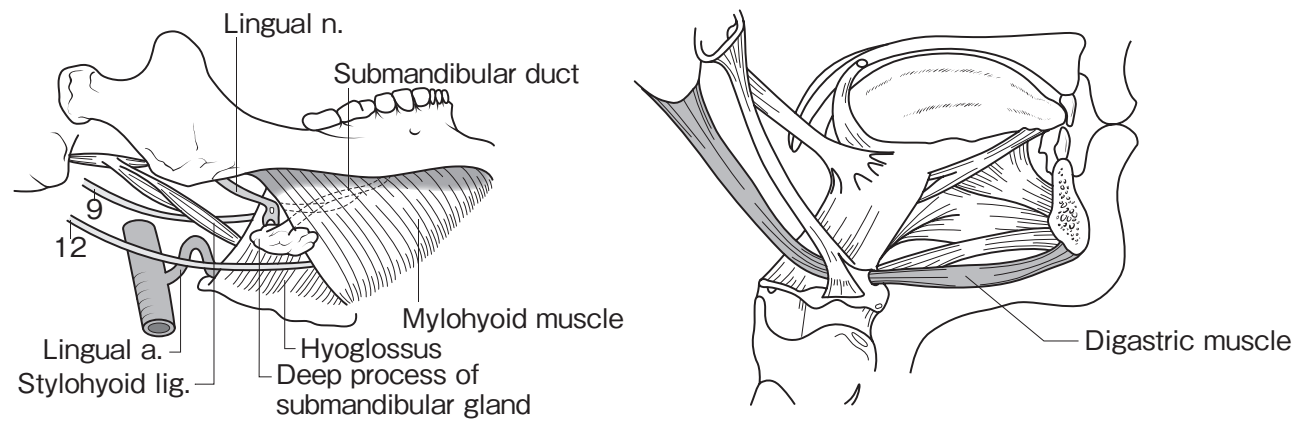

Fig. 2 Position of hypoglossal nerve under digastrics muscle

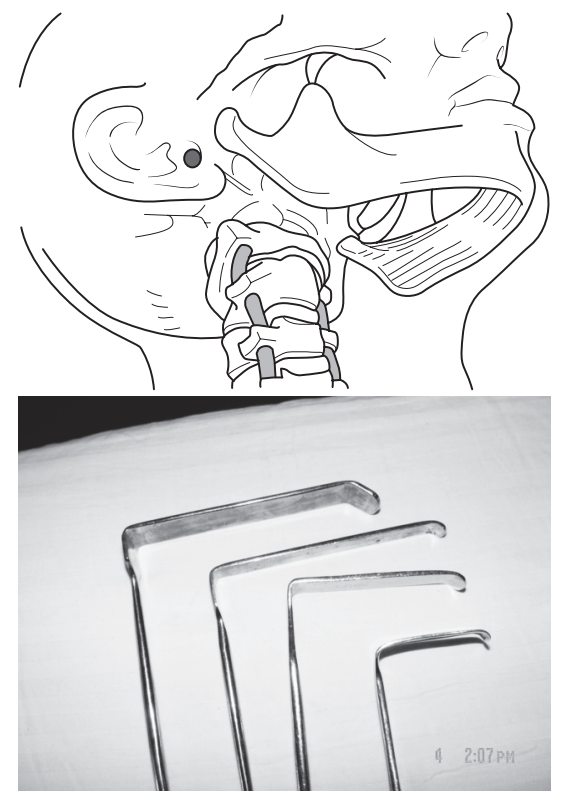

Fig. 3 Position of head and long Langenbeck's retractors
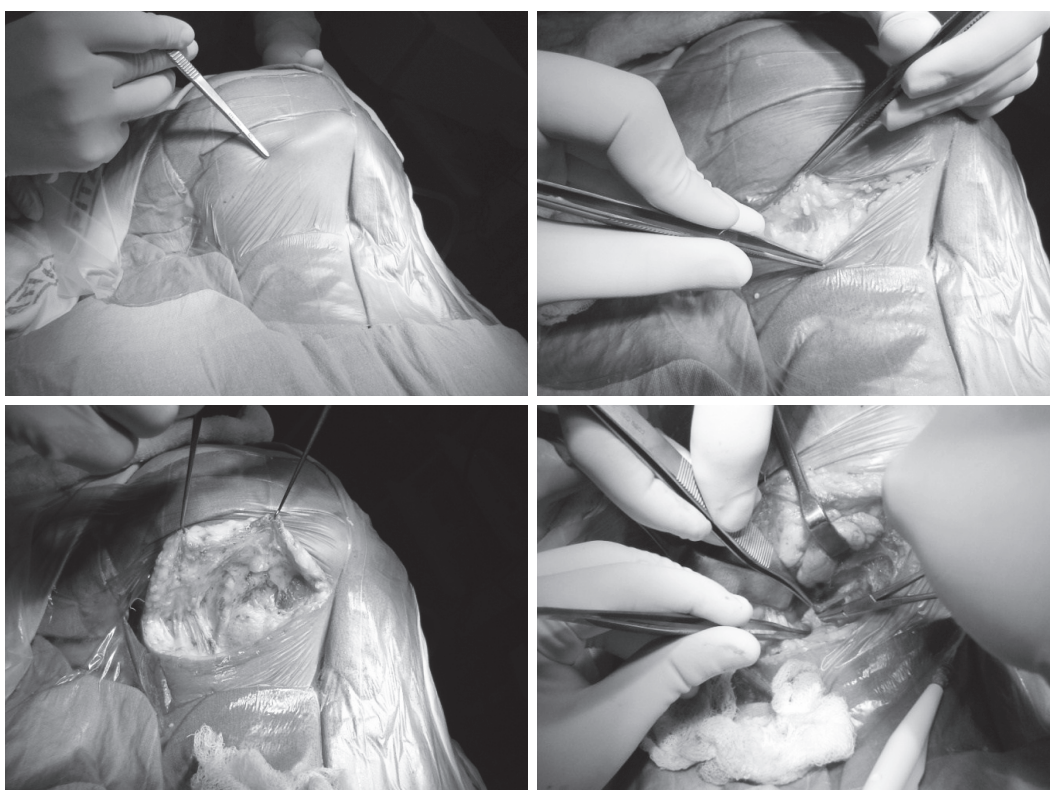

Fig. 4 Steps of exposure 
process and a $3.5 \mathrm{~mm}$ tap was passed for securing a hold on the odontoid process which could be reduced by a gentle upward pull to reduce the distance between the anterior arch of atlas and odontoid process. The joints were grafted with tricoricate wedge graft harvested from the iliac crest or artificial bone from Surgiwear Company India.

When the atlanto-axial dislocation could not be reduced or there is significant basilar invagination the odontoid process was drilled out similar to the transoral technique to decompress the cervicomedullary junction. In 4 cases of congenital fixed dislocations, the odontoid had to be excised.

\section{Fixation techniques}

\section{Screw plate technique}

The anterior surface of the lateral mass of $\mathrm{C} 1$ was cleared of soft tissue. $5 \mathrm{~mm}$ above the midpoint of the $\mathrm{C1}-$ C2 joint a hole was drilled with a $3 \mathrm{~mm}$ drill bit directed 20 degrees upward and outwards (direction and length based on preoperative CT scan analysis) for $15 \mathrm{~mm}$ to 20 $\mathrm{mm}$ depth. $4 \mathrm{~mm}$ thick cortical titanium screws of $18 \mathrm{~mm}$ to $20 \mathrm{~mm}$ length were passed through a $3.5 \mathrm{~mm}$ thickness titanium bone compression plate (used for treatment of radius or clavicle fracture treatment). The lower hole was adjusted over the anterior surface of the $\mathrm{C} 2$ body just above the $\mathrm{C} 2-\mathrm{C} 3$ disc space and the drill hole was made

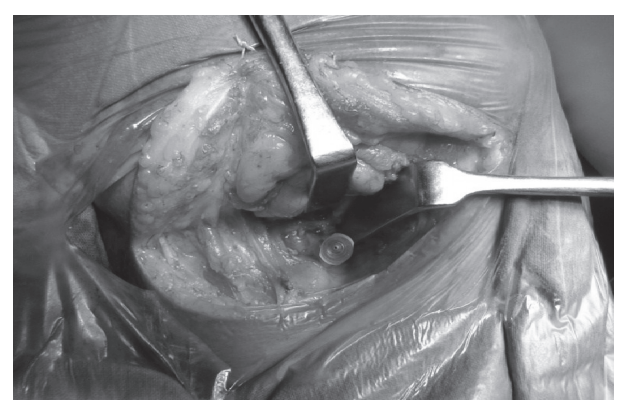

Fig. 5 Anterior surface of axis vertebra marked with needle for check X-ray with plate in position directed 20 degrees medially and depth according to calculations on the preoperative CT scan, usually $18 \mathrm{~mm}$ to $20 \mathrm{~mm}$, and, another $4 \mathrm{~mm}$ cortical screw was passed to secure the plate. Before fixing the lower screw the head was extended rotation corrected and positioned to reduce the atlanto-axial dislocation which was confirmed with intraoperative "C" arm imaging. Procedure was repeated on opposite side (Fig. 6, 7).

\section{Transarticular $\mathrm{C} 2-\mathrm{C} 1$ screw technique}

The sub-facetal surface of the $\mathrm{C} 2$ was cleared of soft tissue bilaterally. The anterior surface of the $\mathrm{C} 2$ body was made flat with a diamond $4 \mathrm{~mm}$ drill. The $\mathrm{C} 1$ lateral mass was cleared of soft tissue till its upper lateral limit could be visualized bilaterally. The skull tongs were used to correct rotation, and achieve satisfactory reduction of the atlanto-axial dislocation by extension which was confirmed by inra operative $\mathrm{X}$-ray imaging. The midpoint of the C2 lateral mass was identified and the entry point chosen was $5 \mathrm{~mm}$ inferomedial to the midpoint, and with a $3.5 \mathrm{~mm}$ drill bit a hole was drilled directed to the upperouter limit of $\mathrm{C} 1$ lateral mass with a 25 degree to 30 degree downward tilt (intraoperative "C" arm imaging used to confirm trajectory). The drill could be seen and felt traversing the joint space bone graft, and passing into the lateral mass of $\mathrm{C} 1$. A $3.5 \mathrm{~mm}$ titanium cortical screw $20^{-}$ $22 \mathrm{~mm}$ was passed to secure the $\mathrm{C} 1-\mathrm{C} 2$ lateral masses. Procedure was repeated on opposite side (Fig. 8, 9).

From a right sided approach it was always easier to pass the contralateral (left) screw so it was performed first, the ipsilateral screw requires retraction of the soft tissues of the pharynx which can add to technical difficulty.

The wound was closed by approximating the mylohyoid muscle, platysma and skin with a drain in the retropharyngeal space which was removed after $48 \mathrm{hrs}$.

Most patients were ambulated next day with a hard cervical collar with full diet next day and discharged from hos-
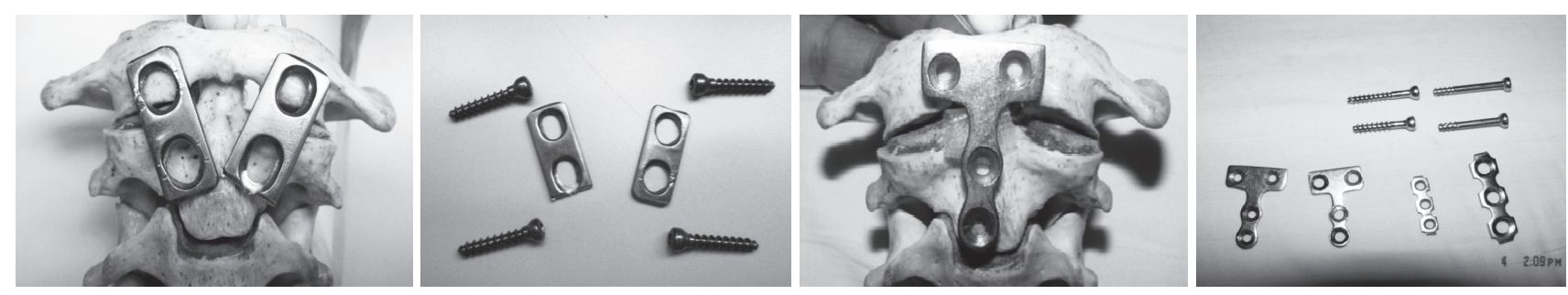

Fig. 6 Implants used for screw plate fixation of $\mathrm{C} 1$ lateral mass and C2 body 


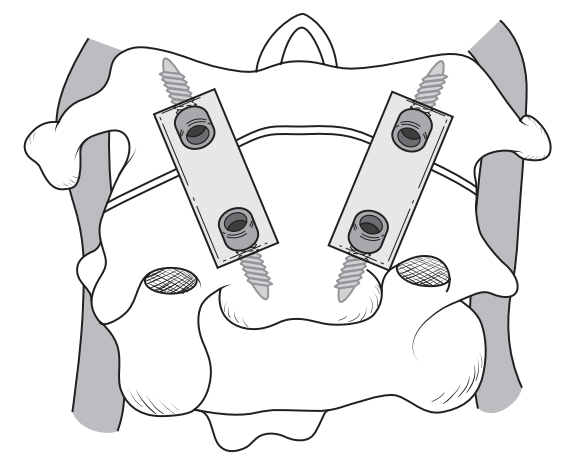

Fig. 7 Position of plate and direction of screws

pital on $3^{\text {rd }}$ day. Postoperative X-rays and CT-scan confirm reduction and fixation (Fig. 10-14).

\section{Results and complications}

Average procedure time $3 \mathrm{hrs}$, no case required blood transfusion, reoperation in 5 cases.

2 screw malposition both ipsilateral (right sided), Reoperated within $48 \mathrm{hrs}$ and screw repositioned correctly (Fig. 15).

One overdistraction of $\mathrm{C} 1-\mathrm{C} 2$ joint due to screw not piercing the $\mathrm{C} 1$ lateral mass and pushing the lateral mass of $\mathrm{C} 1$ away from $\mathrm{C} 2$ (because of inadequate drilling of $\mathrm{C} 1$ lateral mass) (Fig. 16). Reoperated on $3^{\text {rd }}$ day and lateral mass of $\mathrm{C} 1$ drilled correctly and screw passed sucessfully.

One inadequate excision of odontoid process due to excessive preoperative backward angulation of odontoid process which had to be removed transorally after 3 weeks.

One case of screw loosening which was due to incorrect plate contouring, Reoperation after 3 weeks when patient had come for first post-operative follow-up (Fig. 17).

Follow-up in $75 \%$ for 24 mths. Rigid fixation in $100 \%$, Mortality $0 \%$.

Transient neuropraxia of marginal mandibular nerve and hypoglossal nerve in 17 cases (Fig. 18). Vertebral artery injury $0 \%$ Image guidance reduntant and implant cost US $\$ 20$.

\section{Discussion}

The success of $\mathrm{C} 1-\mathrm{C} 2$ surgery depends upon adequate reduction and decompression of the cervicomedullary junction followed by immediate rigid fixation of the atlantoaxial joint, and ultimately, successful bony fusion of the $\mathrm{C} 1-\mathrm{C} 2$ joint. During atlanto-axial joint fixation surgery

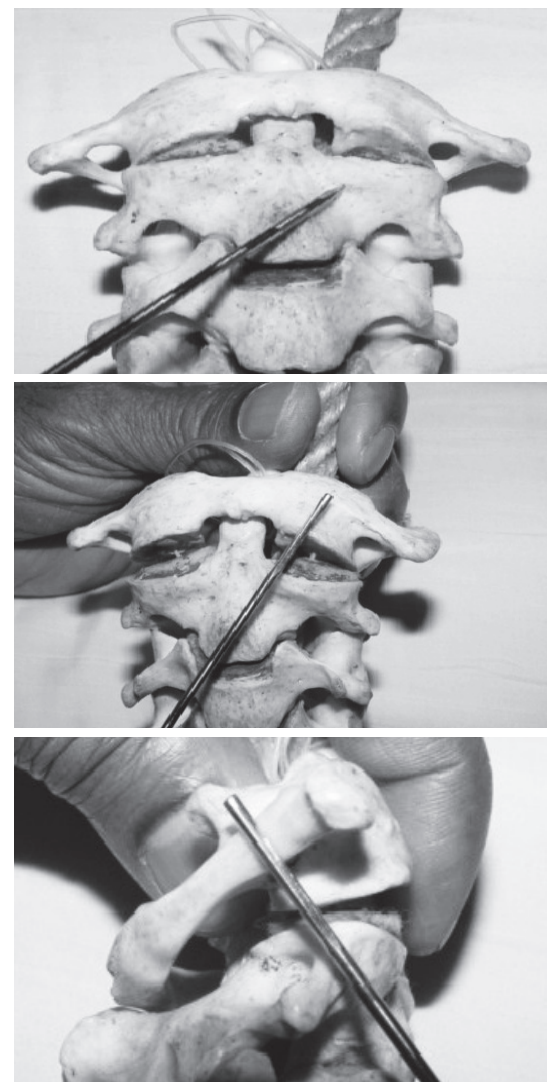

Fig. 8 Trajectory for transarticular screws

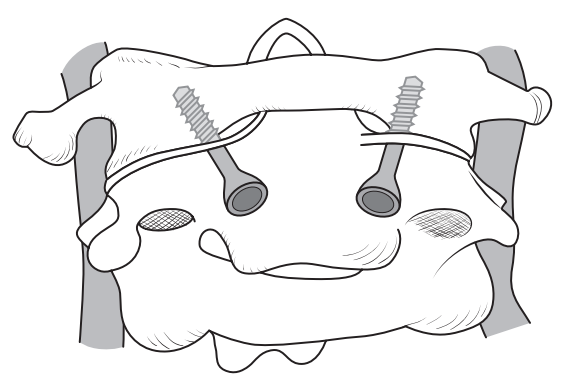

Fig. 9 Anterior transarticular screw position

the main goal of the operation is adequate exposure of the atlanto-axial joints, reduction of joint malposition, decortications of the joint cartilage, bleeding from the endplates on either side for osteoinduction, and, adequate quantity bone grafting which will remain under compression. Thus the entire focus of $\mathrm{C} 1-\mathrm{C} 2$ surgery revolves around manupilation bone grafting and fixing the $\mathrm{C} 1-\mathrm{C} 2$ joint along the line of weight transmission.

As rotation is the main movement at $\mathrm{C} 1-\mathrm{C} 2$, the technique which stops rotation between the joint surfaces is destined for success ${ }^{2}$. All metallic implants are destined 


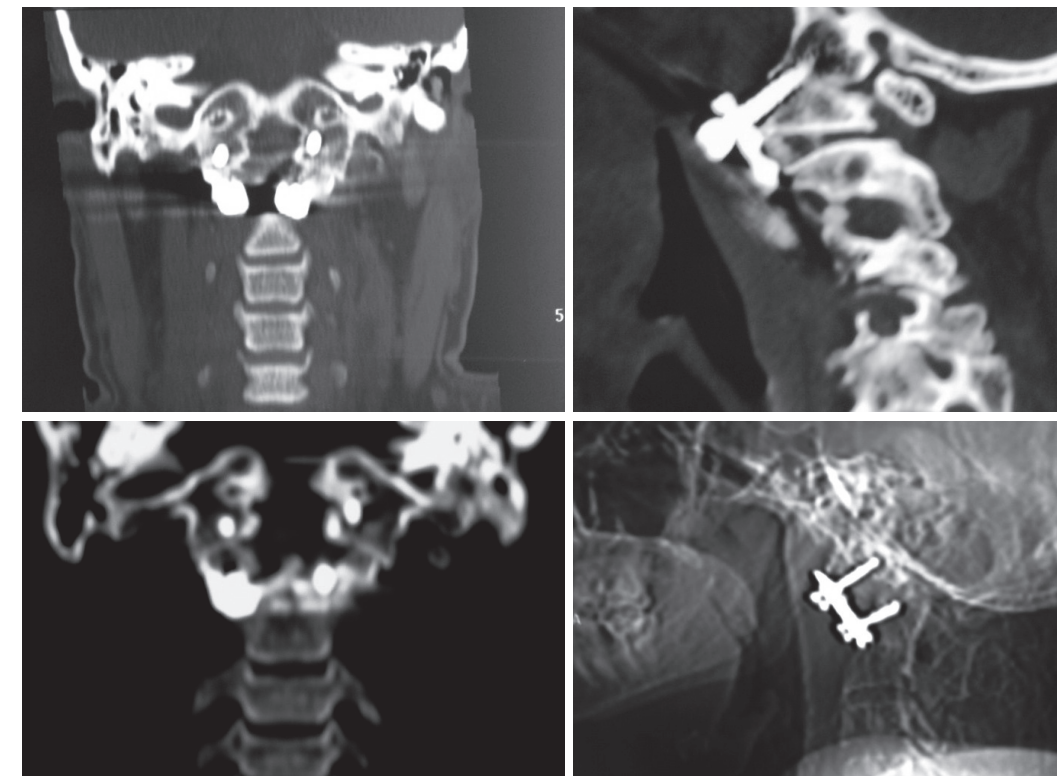

Fig. 10 Postoperative CT scan showing screw plate position with bone graft in C1-C2 joint
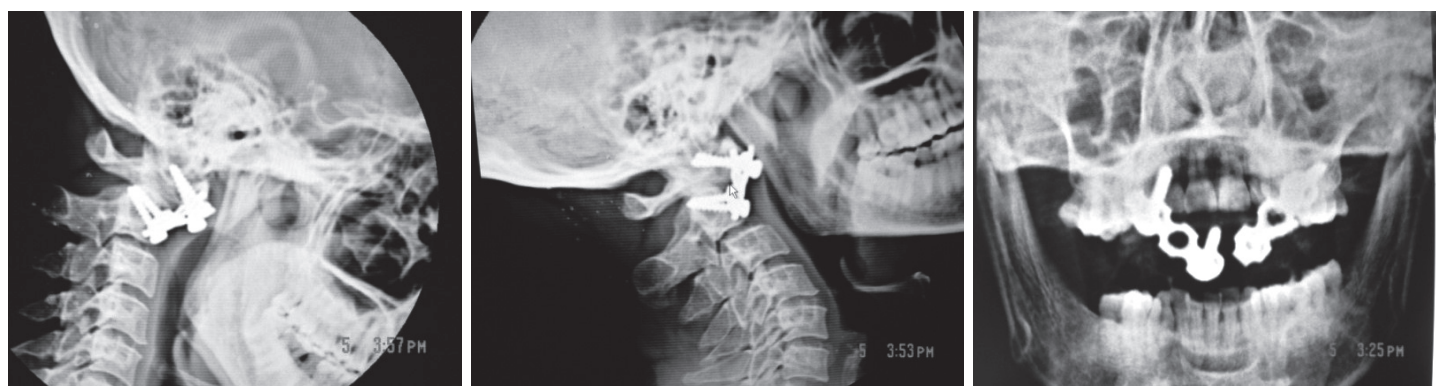

Fig. 11 Postoperative dynamic $\mathrm{X}$-rays of a case of atlanto-axial dislocation showing rigid fixation with $\mathrm{C} 1$ lateral mass and $\mathrm{C} 2$ body screw-plate rigid fixation
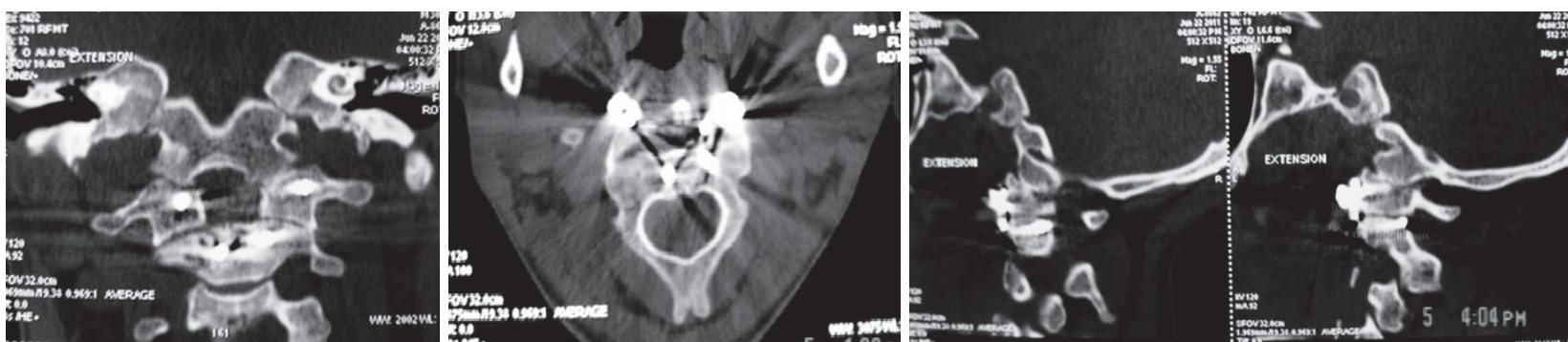

Fig. 12 CT scan images showing screw position of $\mathrm{C} 1$ lateral mass and C2 body screw with bone graft in C1-C2 joint

for failure and their role is only till bony fusion of the joint is complete. So achieving solid bony fusion across the joint should be the ultimate goal of the operation.

Over the past century, steady advances have been made in fixating an unstable atlanto-axial complex. Current options for fixation of the atlanto-axial complex include posterior clamps, posterior wiring techniques, $\mathrm{C} 1-\mathrm{C} 2$ transarticular screw fixation, posterior $\mathrm{C} 1$ lateral mass screw with $\mathrm{C} 2$ pars or pedicle screw fixation ${ }^{3)}$.

The posterior wiring techniques, $\mathrm{C} 1-\mathrm{C} 2$ clamps Hartshill sublaminar wire relied on onlay grafting or grafting between the posterior arch of $\mathrm{C} 1$ and lamina of $\mathrm{C} 2$. These techniques fail in rotation and thus came to disrepute.

In 1986 Magerl $^{4)}$ described the posterior transarticular C2-C1 fixation technique (PTS) which had 100 percent fixation and fusion rate. However, there was a significant 


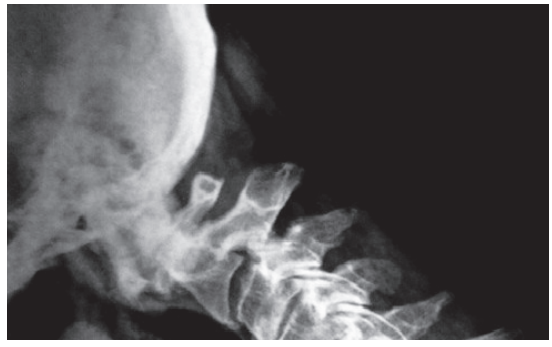

Fig. 13 Preoperative and postoperative $X$-rays showing rigid fixation of atlanto-axial dislocation with anterior transarticular screws bilaterally and type of screws used
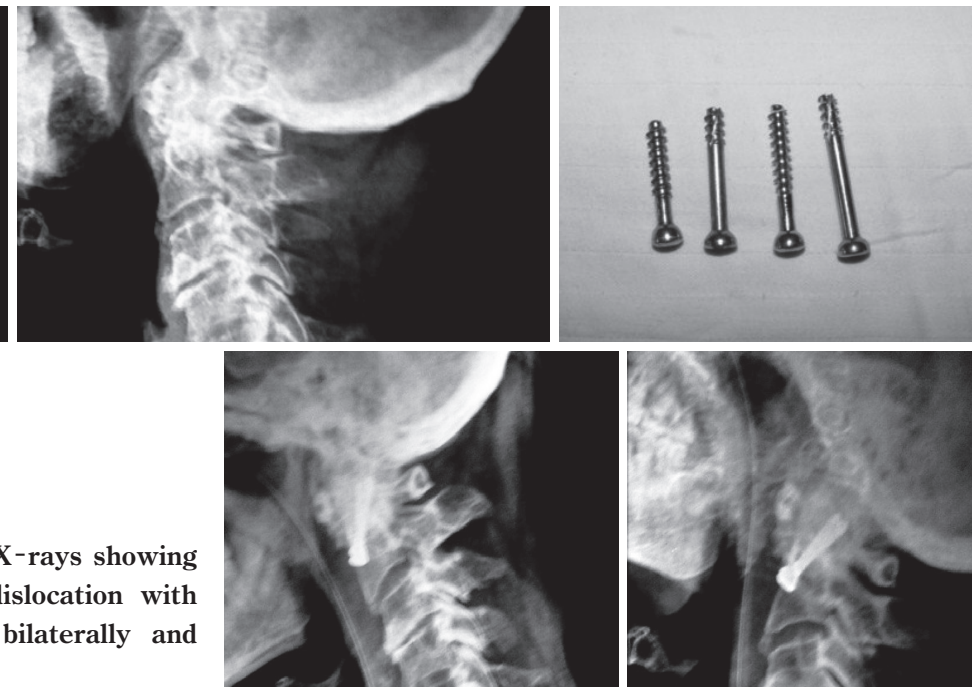

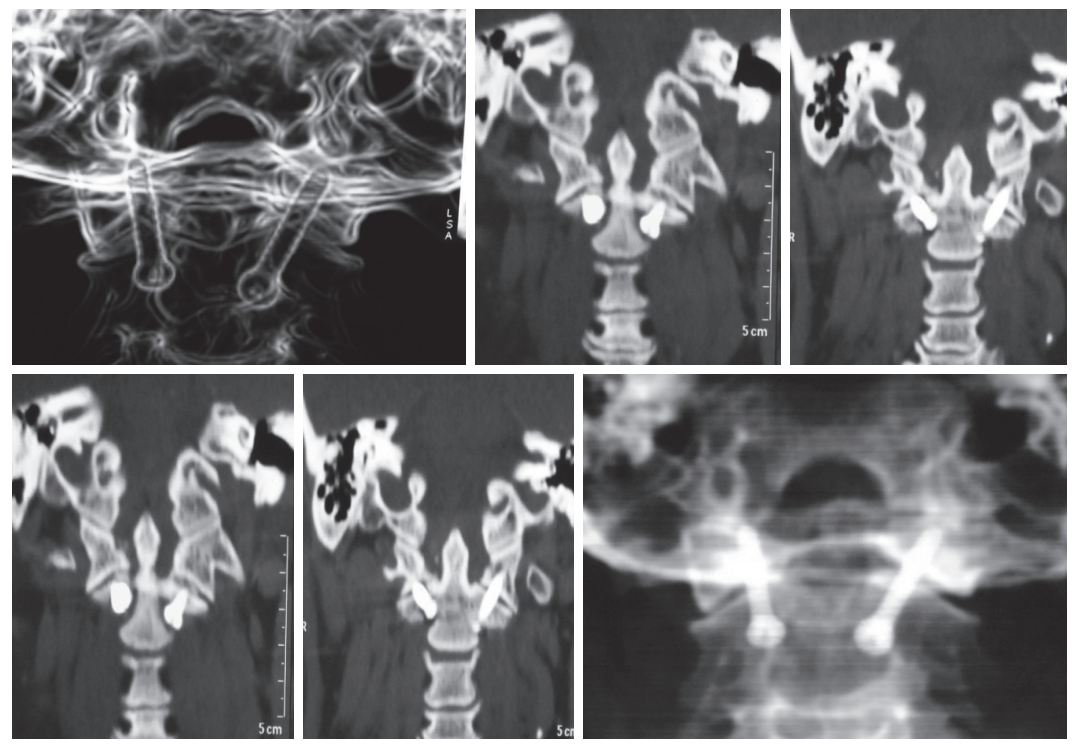

Fig. 14 CT scan and tomogram showing correct position of anterior transarticular screws

chance of vertebral artery injury with devastating complications. Anatomical variation in the $\mathrm{C} 2$ pedicle anatomy on pre-operative imaging has prevented passage of posterior transarticular screw in a significant number of patients $^{5)}$.

Goel $^{6)}$ in 1994 published posterior C1 mass screw and $\mathrm{C} 2$ pedicle screw with plate to fix the $\mathrm{C} 1 \mathrm{C} 2$, later Harm's $^{7)}$ et al in 2001 popularized the technique of poly axial screw rod technique for the same. With both these technique's the incidence of vertebral artery injury reduced but still persists.

Recent literature has focused on the use of intraoperative image guidance to avoid vertebral artery injury.
Intraoperative bleeding from the paravertebral venous plexus and manipulation of the $\mathrm{C} 2$ ganglion to avoid injury remain surgical problems for surgeons ${ }^{8 \sim 10)}$.

In a recent comparison of Harm's technique (Group H) with Magerl's technique (Group M), the major complications were vertebral artery injury $(2.1 \%$ in Harms, $13.1 \%$ in Magerl's, $\mathrm{p}=0.05)$ and screw fracture $(2.1 \%$ in Group H, $9.2 \%$ in Group M, p>0.05). Fusion rate at the end of follow-up was not-significantly higher in Group $\mathrm{H}$. C1$\mathrm{C} 2$ range of movements in flexion/extension at the end of follow-up was lower in Group $\mathrm{H}^{11)}$.

Also all posterior surgical techniques involve massive disruption of the musculo-ligamentous complex which are 

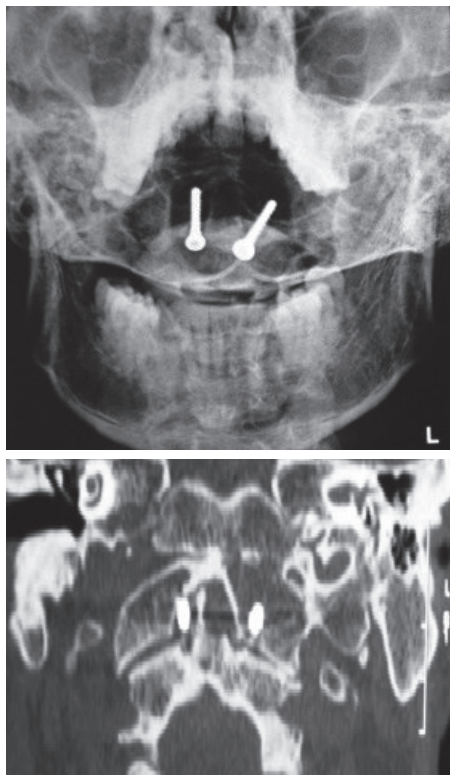

Fig. $15 \mathrm{X}$-ray and CT scan showing malposition of right sided anterior transarticular screw
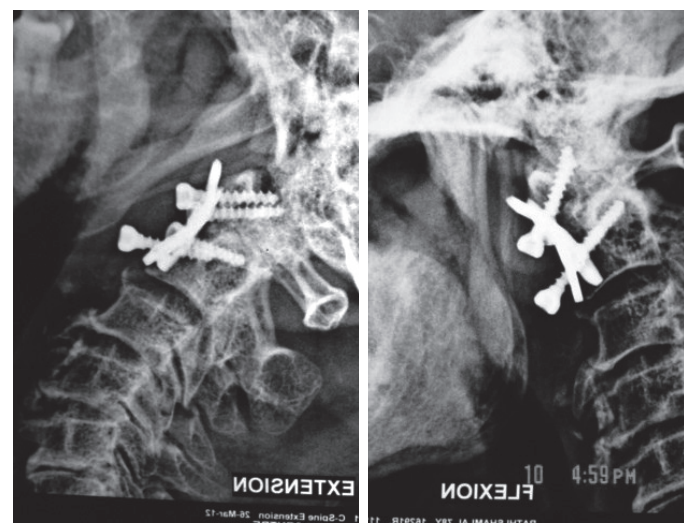

Fig. 17 Dynamic $\mathrm{X}$-ray showing rigid fixation, but, screw pullout due to bent plate on one side

essential for spinal stability and thus these techniques are contradictory to success by adding insult to injury and against the principle of minimal invasion ${ }^{12,13)}$.

During the anterior extrapharyngeal approach the atlanto-axial joint reduces in extension which is used in supine position for surgery. The vertebral artery, venous plexus and C2 nerve root or ganglion are at no risk of injury in the anterior extrapharyngeal approach. The dissection is through muscle planes which do not have any postoperative adverse consequence on spinal balance and stability. From the anterior approach the $\mathrm{C} 1-\mathrm{C} 2$ joint exposure, decortication and bone grafting is without any anatomical constraints.

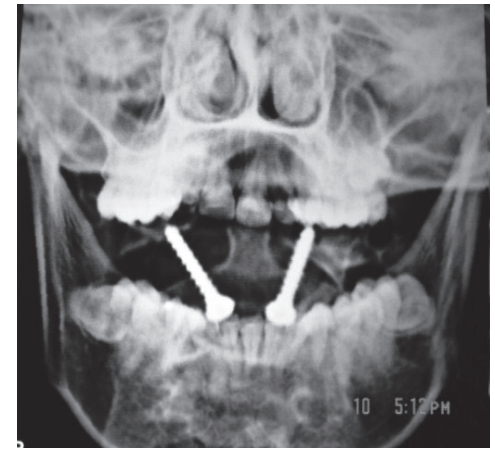

Fig. 16 Overdistraction of C1-C2 joint due to incomplete drilling of $\mathrm{C} 1$ lateral mass on right side
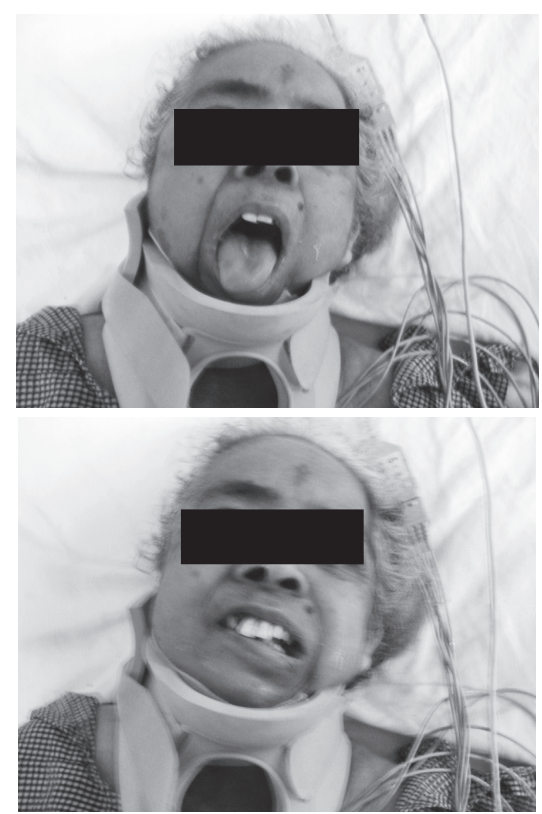

Fig. 18 Immediate postoperative tounge and lower lip weakness due to retraction induced neurapraxia of hypoglossal and marginal mandibular nerve

Anterior $\mathrm{C} 1-\mathrm{C} 2$ arthrodesis with separate unilateral approach for each joint has been described earlier by Barbour $^{14)}$ and Whitesides ${ }^{15)}$.

Unilateral approach and bilateral anterior screw plate fixation with wedge bone grafting of the $\mathrm{C} 1-\mathrm{C} 2$ joint has not been described in literature.

Since Barbour's description in 1971 of anterior transarticular screws (ATS), many authors have published their experiences, Lesoin $(1976)^{16)}$, Apostolides $(1987)^{17)}$, Lu and Ebraheim (1998) ${ }^{18)}$ Vaccaro (1999) ${ }^{19)}$, Knöller's 11 cases $(1999)^{22)}$, Reindl $(2003)^{13)}$ and Reimann $(2004)^{12)}$ with the largest series of 16 cases. All the authors have written about the simplicity of the technique and impor- 
tance of preserving the posterior paraspinal musculature.

Kim et al $(2004)^{20)}$ showed in a cadaveric analysis that ATS was comparable to PTS and the commonly prevalent $\mathrm{C} 1$ lateral mass and $\mathrm{C} 2$ pedicle screw rod/plate techniques. Sen et al $(2005)^{2)}$ also showed that ATS and PTS were comparable and bone grafting in the joint was reduandant. Koller et al $(2006)^{21)}$ in an technical analysis have suggested modification in the ATS technique with a transcorporal pathway to enhance fixation of the $\mathrm{C} 2$ body.

Posterior fixation of the atlanto-axial joint is a challenging procedure with inherent risk of vascular injury (vertrbral artery) and neural injury. Magerl's posterior transarticular screw fixation provides the most rigid fixation because it restricts rotational movement but is difficult in significant percentage due to variable anatomy of the axis pedicle and the course of the vertebral artery and thus was replaced by the technicque of $\mathrm{C} 1$ lateral mass and $\mathrm{C} 2$ pedicle screw rod fixation, which has become the procedure of choice. However the risk of injury to the vertebral artery and haemorrhage from the perivertebral venous plexus remain deterrents to most surgeons.

Anterior extrapharyangeal approach allows reduction of the atlanto-axial dislocation, opportunity for bone grafting of the joint and with anterior $\mathrm{C} 1$ lateral mass and $\mathrm{C} 2$ body screw plate fixation or anterior transarticular screws provides rigid fixation without any risk to the vertebral artery venous plexus or spinal cord.

\section{REFERENCES}

1) Stevenson GC, Stoney RJ, Perkins RK, et al : A transcervical transclival. approach to the ventral surface of the brain stem for removal of a clivus chordoma. J Neurosurg 24:544-551, 1966

2) Sen MK, Steffen T, Beckman L, et al: Atlantoaxial fusion using anterior transarticuar screw fixation of $\mathrm{C} 1-\mathrm{C} 2:$ technical innovation and biomechanical study. Eur Spine $J$ 14:512518, 2005

3) Mummaneni PV, Haid RW : Atlantoaxial fixation : overview of all techniques. Neurol India $53: 408-415,2005$

4) Magerl F, Seemann PS : Stable posterior fusion of the atlas and axis by transarticular screw fixation. Kehr P, Weidner A (eds) : Cervical Spine. Vol. 1. New York, Springer, 1987, pp322327

5) Abou Madawi A, Solanki G, Casey AT, et al : Variation of the groove in the axis vertebra for the vertebral artery-implications for instrumentation. J Bone Joint Surg Br 79:820-823,
1997

6) Goel A, Laheri V : Plate and screw fixation for atlanto-axial subluxation. Acta Neurochir 129：47-53, 1994

7) Harms J, Melcher RP : Posterior C1-C2 fusion with polyaxial screw and rod fixation. Spine $26: 2467-2471,2001$

8) Dwarkanath S, Suri A, Sharma BS: Transarticular screw fixation using neuronavigation: Technique. Indian J Orthop 41 : 318-321, 2007

9) Wright NM, Lauryssen $\mathrm{C}$ : Vertebral artery injury in $\mathrm{C} 1-2$ transarticular screw fixation : results of a survey of the AANS/ CNS section on disorders of the spine and peripheral nerves. American Association of Neurological Surgeons/Congress of Neurological Surgeons. J Neurosurg 88：634-640, 1998

10) Yamazaki M, Okawa A, Sakuma T, et al : Anomalous vertebral arteries in the extra- and intraosseous regions of the craniovertebral junction visualized by 3 -dimensional computed tomographic angiography : analysis of 100 consecutive surgical cases and review of the literature. Spine $37:$ E1389-1397, 2012

11) Vergara P, Bal JS, Hickman Casey AT, et al : C1-C2 posterior fixation: are 4 acrews better than 2? Neurosurgery 71 (1 Suppl) : 86-95, 2012

12) Reimann B, Eggers C : Die transartikuläre Verschraubung von ventral zur Stabilisierung der Dens-Axis-Fraktur bei Osteoporose im hohen Alter: Eine gering invasive Alternative zum dorsalen Vorgehen. 68th Annual Meeting DGU, Berlin, Germany (lecture).

13) Reindl R, Sen M, Aebi M : Anterior instrumentation for traumatic C1-C2 instability. Spine 28: E329-333, 2003

14) Barbour JR: Screw fixation in fractures of the odontoid process. S Aust Clinics $\quad \mathbf{5}: 20,1971$

15) Whitesides TE Jr, Kelly RP : Lateral approach to the upper cervical spine for anterior fusion. South Med J 59 : 879-883, 1966

16) Lesoin F, Autricque A, Franz K, et al : Transcervical approach and screw fixation for upper cervical spine pathology. Surg Neu rol 27:459-465, 1987

17) Apostolides PJ, Theodore N, Karahalios DG, et al : Triple anterior screw fixation of an acute combination atlas-axis fracture. J Neurosurg 87:96-99, 1997

18) Lu J, Ebraheim NA, Yang H, et al : Anatomic considerations of anterior transarticular screw fixation for atlantoaxial instability. Spine 23: 1229-1235, 1998

19) Vaccaro AR, Lehman AP, Ahlgren BD, et al : Anterior $\mathrm{C} 1-\mathrm{C} 2$ screw fixation and bony fusion through an anterior retropharyngeal approach. Orthopedics $22: 1165-1170,1999$

20) Kim SM, Lim TJ, Paterno J, et al : Biomechanical comparison of anterior and posterior stabilization methods in atlantoaxial instability. J Neurosurg（3 Suppl） 100：277-283, 2004

21) Koller H, Kammermeier V, Ulbricht D, et al : Anterior retropharyngeal fixation $\mathrm{C} 1-2$ for stabilization of atlantoaxial instabilities : study of feasibility, technical description and preliminary results. Eur Spine J 15:1326-1338, 2006

22) Knöller S, Jeszensky D, Willms R, et al : Transaxiale Spongiosaplastik und ventrale, temporäre atlantoaxiale Fixation zur Therapie der Denspseudoarthrose [in german]. Z Orthop 137 : 232-235, 1999 